\title{
Creation of Polymer Coatings for Improving of Protective Properties of Surfaces
}

\author{
A.A. Orekhov', Ying Sun ${ }^{2}$ \\ ${ }^{1}$ Moscow Aviation Institute (National Research University), Volokolamskoeshosse, 4, 125993, Moscow, Russia \\ ${ }^{2}$ Department of Mechanical Engineering, Hangzhou Xiaoshan Technician College, 311200, 448 Tonghui South \\ Road, Xiaoshan District, Hangzhou Zhejiang, China \\ ${ }^{1}$ lsk.orekhov@gmail.com
}

Article History: Received: 11 January 2021; Accepted: 27 February 2021; Published online: 5 April 2021

\begin{abstract}
In this paper, the preparation of polymer coatings on the surface of metal structural elements is considered to improve their physical, mechanical and strength properties. It is shown that the behavior of substrate samples under mechanical loads can be estimated using mathematical modeling methods. The properties of coatings and the mechanical properties of coated and uncoated metal plates have been evaluated. Methods for constructing mathematical models of metal plates of various structures are proposed.

Keywords:Strength, modulus of elasticity, coatings, mechanical properties.
\end{abstract}

\section{Introduction}

One of the most widely used types of polymer coatings on the surface of metal products are paints and varnishes, i.e. filled polymers[1-8]. All powder paints and varnishes can be divided into two large groups: thermoplastic and thermosetting.

Thermoplastic paints and varnishes form coatings without chemical reactions, only due to the fusion of particles and granules of the filled polymer when heated. The coatings formed from them are thermoplastic and reversible. They are mainly used to obtain functional coatings - chemically resistant, anticorrosive, antifrictional, and electrical insulating[1-]. The coatings are usually applied in thick layers - 250 microns or more. Typical applications include protection of wires, pipes, splined shafts and friction units, electrical insulation of tires, switches and other products.

Thermosetting paints, in contrast to thermoplastic paints, form coatings through chemical reactions when heated. Such coatings have a three-dimensional structure, they are not melting and insoluble, that is, irreversible. Thermosetting paints are used to obtain both functional coatings and protective and decorative[9-12]. For the production of functional coatings, compositions based on epoxy resins are most widely used. They are applied in layers of 100-150 microns on a heated surface in a fluidized bed apparatus (repeatedly alternating heating and immersion in powder) or by jet spraying. This is how coatings are applied to rotors and stators of electric motors, to pipes - from the outside and from the inside, metal fittings, mesh, coils.

The main share of consumption of thermosetting paints, however, falls on protective and decorative coatings, for which appearance is most important. Such coatings usually have a small thickness (25-100 microns). The most common way to apply them is by electrostatic spraying.

Most powder paints and varnishes consist of a small number of components: a film former (polymer or oligomer), pigments and fillers that increase the operational and mechanical characteristics of the base polymer, auxiliary substances and other targeted additives [13-18].

Epoxy paints are the first type of thermosetting powder materials, mastered in the industry, which is still in use. Despite the fact that epoxy paints can form coatings with good decorative properties, they are used primarily for functional coatings. Existing epoxy paints are varied in composition. Depending on the type of resin and hardener, they form coatings with various properties, in particular, with the appropriate choice of raw materials, paints and coatings are obtained that can contact with food. The main disadvantage of epoxy coatings is low resistance to weathering.

According to their purpose, paints are divided into functional and protective and decorative paints.

The main area of application for functional paints is electrical insulation and corrosion protection. Epoxy paints have become a good alternative to many types of electrical insulation previously used in industry, such as: taping, compounding, painting (impregnation) with liquid paints, etc. Due to the complex of valuable properties, 
simplicity and low cost of electrical insulation, epoxy powder paints and compounds have become dominant in electrical and electronic industry.

Epoxy powder paints are widely used for anti-corrosion purposes. The coatings are distinguished by their low cost, ease of maintenance and long-term protection in various aggressive environments. They are characterized by flexibility, impact resistance, low permeability, good heat resistance and adhesion.Paints can be applied in one way or another to a cold or preheated surface. After curing, they can be used for a long time at temperatures up to $150^{\circ} \mathrm{C}$. As electrical insulating in terms of resistance to heating, they are classified as class B $\left(130^{\circ} \mathrm{C}\right)$.

In contrast to materials for functional purposes, protective and decorative paints are intended for obtaining coatings of small thickness[19-24]. They are selected according to specific requirements. The fields of application of such formulations are varied. First of all, these are drying drums, garden tools, door furniture fittings, microwave ovens, refrigerator parts, racks, toys.

Epoxy-polyester (hybrid) paints are more resistant than epoxy paints to yellowing caused by overheating during curing. Chalking and discoloration of coatings appear to a lesser extent during operation in atmospheric conditions. However, hybrid coatings, like epoxy coatings, are not recommended for use in sunlight. The mechanical properties (flexibility, hardness, impact resistance) of coatings are basically the same as those of epoxy, and the resistance to chemicals is slightly lower.

\section{Creation of polymer coatings on metal surfaces}

Particles of dry powder, applied to a hard surface, are retained on it mainly due to the forces of electrostatic attraction. Wetting occurs when the powder particles are melted. Impurities and impurities present on the surface interfere with wetting. As a result, proper contact of the melt with the surface to be painted does not form, which negatively affects the adhesion and sometimes the appearance of the coatings.

Depending on the conditions of manufacture, processing and storage of metal, various types of contamination may be present on its surface. Distinguish between organic pollution (mineral oils and greases, soaps, residues of polishing pastes and liquids) and inorganic nature (metal oxides and hydroxides, slags, shop dust, etc.)

When choosing a cleaning method, the nature of pollutants and the degree of surface contamination by them are usually taken into account. To remove oil and grease contaminants, which are the most common, aqueous alkaline compounds, detergent solutions and organic solvents are usually used. Fatty acids and components of polishing pastes require more concentrated alkaline solutions and, at the same time, the use of mechanical stress. Oxides are usually removed with acids, and the process is accelerated with increasing acid strength and concentration and increasing temperature. Particulate contamination, which includes shop dust, shop soot, solid components from polishing liquids and pastes, is usually removed simultaneously with oxides when using acidic formulations, but good results can be achieved in the case of alkaline detergents.

Powder paints are applied to parts either by electrostatic spraying, immersion in a fluidized bed (with or without electrification of particles), or by gas plasma spraying. Electrostatic spray is the most convenient and provides the best control of the coating thickness. It has become the main coating method in the industry.

In a coating installation, the filled polymer powder in a special hopper (feeder) is fluidized (fluidized) using compressed air. The ejector picks up the powder from the hopper and transfers it to the spray gun. The control panel is used to control the supply of powder and air, as well as to maintain the spray parameters. In the atomizer, an electric charge is imparted to the powder by ion bombardment in an electric field (corona charging method) or by friction (tribostatic charging method).

Corona charging systems supply high voltage to the charging electrodes of the spray gun and a strong electric field is created between the spray gun and the grounded part.

In most cases, corona charging systems use the negative polarity of the charging electrode. The electric field strength reaches its maximum value at the end of the charging electrode, and when a certain level is reached, a corona discharge occurs here. Corona discharge is a type of cold plasma in which free electrons appear in the corona region, which fill the space between the atomizer and the part. These electrons attach to air molecules, thus creating negative ions. If the electric field outside the corona discharge has a sufficient strength, then the ions, in turn, will attach to the powder particles as it is sprayed. 
As a result, a cloud of charged powder particles and free (non-aligned) ions is created between the spray gun and the part. The combined charge of the powder particles and free ions that make up the cloud is called "space charge". Space charge creates its own electric field, which interacts with the field of the high voltage electrode and helps the powder particles to deposit on a grounded substrate.

Corona charging is the most widely used powder charging technology. Its advantages are due to the following advantages:

- high charging efficiency of almost all powder materials used in coatings,

- high performance coating systems using corona charging,

- relatively low sensitivity to ambient humidity,

- equipment reliability and low maintenance and repair costs.

Conventional corona charging systems also have their drawbacks, which are caused by the strong electric field between the spray gun and the part. So, in some cases, a strong electric field can make it difficult to apply the coating in corners and in places of deep grooves. In addition, improper selection of the electrostatic parameters of the spray gun and the distance from the gun to the part can cause reverse ionization and degrade the quality of the coating.

\section{Evaluation of the strength properties of coated metal elements}

From the point of view of strength calculations, thin-walled metal structural elements with polymer coatings can be presented in the form of two- or three-layer plates (depending on whether the coating is applied on one or both sides) with a tougher metal middle layer and much more pliable outer layers-coatings [25-27]. Currently, not many experimental and theoretical works are known in which the analysis of the macroscopic mechanical behavior of such structural elements is carried out taking into account the effects of the influence of residual stresses[28-30]. It is possible to note a wide variety of works in the field of research of functional-gradient thinwalled structures with coatings (see, for example, [26-28] and references therein). However, in such structures it is usually assumed that the rigidity of the surface layers is higher than that of the inner region. These are structures such as, for example, metal products with ceramic coatings, biological objects with external protective shells, etc. Thin-walled structures with a rigid middle layer and pliable thin outer layers have received little attention. In linear problems of statics, in fact, as experiments show, the effect of thin coatings can be neglected. However, in more specific problems (for example, under conditions of finite deformations, nonlinear elasticity), neglecting the effect of thin coatings can lead to significant calculation errors[31-37]. Significant effects associated with the influence of thin polymer coatings on the stress-strain state of thin-walled metal structures can manifest themselves in stability tests and can be associated with the action of residual stresses.

\section{Conclusions}

From the presented brief review of existing paint and varnish coatings and their tests, it can be concluded that none of the developed methods allows one to obtain definite estimates of the elastic characteristics of coatings. On the other hand, knowledge of the elastic properties of coatings makes it possible to simulate their behavior under various operating conditions using widely used commercial finite element packages such as NASTRAN, ANSYS, LS DYNA, and others. The study of this issue on the example of testing steel plates with thin polymer coatings requires separate experimental and theoretical work.

\section{Acknowledgements}

The work was carried out with the financial support of the state project of the Ministry Science and Higher Education of the Russian Federation "Theoretical and experimental research in production and processing of advanced metal and composite materials based on aluminum and titanium alloys", project No. FSFF-2020-0017.

\section{References}

1. N.A. Bulychev, E.L. Kuznetsova, V.V. Bodryshev, L.N. Rabinskiy. Nanotechnological aspects of temperature-dependent decomposition of polymer solutions, Nanoscience and Technology: An International Journal, 2018, Vol. 9 (2), p.91-97.

2. N.A. Bulychev, A.V. Ivanov. Effect of vibration on structure and properties of polymeric membranes, International Journal of Nanotechnology, 2019, Vol. 16, Nos. 6/7/8/9/10, pp. $334-343$. 
3. N.A. Bulychev, A.V. Ivanov. Study of Nanostructure of Polymer Adsorption Layers on the Particles Surface of Titanium Dioxide, International Journal of Nanotechnology, 2019, Vol. 16, Nos. 6/7/8/9/10, pp. $356-365$.

4. O.A. Butusova. Surface Modification of Titanium Dioxide Microparticles Under Ultrasonic Treatment, International Journal of Pharmaceutical Research, 2020, Vol. 12, I. 4, pp. 2292-2296.

5. B.A. Garibyan. Mechanical Properties of Electroconductive Ceramics, International Journal of Pharmaceutical Research, 2020, Vol. 12, Supplementary Issue 2, pp. 1825-1828.

6. B.A. Garibyan. Enhancement of Mechanical Properties of Inorganic Glass under Ultrasonic Treatment, International Journal of Pharmaceutical Research, 2020, Vol. 12, Supplementary Issue 2, pp. 1829. 1832.

7. A.N. Tarasova. Vibration-based Method for Mechanochemical Coating Metallic Surfaces, International Journal of Pharmaceutical Research, 2020, Vol. 12, Supplementary Issue 2, pp. 1160-1168.

8. O.A. Butusova. Stabilization of Carbon Microparticles by High-Molecular Surfactants, International Journal of Pharmaceutical Research, 2020, Vol. 12, Supplementary Issue 2, pp. 1147-1151.

9. N.A. Bulychev, A.V. Ivanov. Nanostructure of Organic-Inorganic Composite Materials Based on Polymer Hydrogels, International Journal of Nanotechnology, 2019, Vol. 16, Nos. 6/7/8/9/10, pp. 344 355.

10. O.A. Butusova. Vinyl Ether Copolymers as Stabilizers of Carbon Black Suspensions, International Journal of Pharmaceutical Research, 2020, Vol. 12, Supplementary Issue 2, pp. 1152-1155.

11. Yu.V. Ioni. Synthesis of Metal Oxide Nanoparticles and Formation of Nanostructured Layers on Surfaces under Ultrasonic Vibrations, International Journal of Pharmaceutical Research, 2020, Vol. 12, Issue 4, pp. 3432-3435.

12. Yu.V. Ioni, A. Ethiraj. Study of Microparticles Surface Modification by Electrokinetic Potential Measuring, International Journal of Pharmaceutical Research, 2020, Vol. 12, Issue 4, pp. 3436-3439.

13. O.A. Butusova. Adsorption Behaviour of Ethylhydroxyethyl Cellulose on the Surface of Microparticles of Titanium and Ferrous Oxides, International Journal of Pharmaceutical Research, 2020, Vol. 12, Supplementary Issue 2, pp. 1156-1159.

14. A.N. Tarasova. Effect of Reagent Concentrations on Equilibria in Water-Soluble Complexes, International Journal of Pharmaceutical Research, 2020, Vol. 12, Supplementary Issue 2, pp. 11691172 .

15. A.N. Tarasova. Effect of Vibration on Physical Properties of Polymeric Latexes, International Journal of Pharmaceutical Research, 2020, Vol. 12, Supplementary Issue 2, pp. 1173-1180.

16. M.O. Kaptakov. Effect of Ultrasonic Treatment on Stability of TiO2 Aqueous Dispersions in Presence of Water-Soluble Polymers, International Journal of Pharmaceutical Research, 2020, Vol. 12, Supplementary Issue 2, pp. 1821-1824.

17. M.O. Kaptakov. Catalytic Desulfuration of Oil Products under Ultrasonic Treatment, International Journal of Pharmaceutical Research, 2020, Vol. 12, Supplementary Issue 2, pp. 1838-1843.

18. M.O. Kaptakov. Enhancement of Quality of Oil Products under Ultrasonic Treatment, International Journal of Pharmaceutical Research, 2020, Vol. 12, Supplementary Issue 2, pp. 1851-1855.

19. Yu.V. Ioni. Effect of Ultrasonic Treatment on Properties of Aqueous Dispersions of Inorganic and Organic Particles in Presence of Water-Soluble Polymers, International Journal of Pharmaceutical Research, 2020, Vol. 12, Issue 4, pp. 3440-3442.

20. N.A. Bulychev, M.A. Kazaryan. Optical Properties of Zinc Oxide Nanoparticles Synthesized in Plasma Discharge in Liquid under Ultrasonic Cavitation, Proceedings of SPIE, 2019, Vol. 11322, article number 1132219.

21. Yu.V. Ioni, A. Ethiraj. New Tailor-Made Polymer Stabilizers for Aqueous Dispersions of Hydrophobic Carbon Nanoparticles, International Journal of Pharmaceutical Research, 2020, Vol. 12, Issue 4, pp. 3443-3446.

22. Yu.V. Ioni. Nanoparticles of noble metals on the surface of graphene flakes, PeriodicoTcheQuimica, 2020, Vol. 17, No. 36, pp. 1199-1211.

23. N.A.Bulychev, L.N. Rabinskiy, Ceramic nanostructures obtained by acoustoplasma technique, Nanoscience and Technology: An International Journal, 2019, 10(3), p. 279-286.

24. N.A.Bulychev, L.N.Rabinskiy, O.V. Tushavina, Effect of intense mechanical vibration of ultrasonic frequency on thermal unstable low-temperature plasma, Nanoscience and Technology: An International Journal, 2020, 11(1), p. 15-21. 
25. V.V.Bodryshev, A.V.Babaytsev, L.N. Rabinskiy, Investigation of processes of deformation of plastic materials with the help of digital image processing,PeriodicoTcheQuimica, 2019, 16(33), p. 865-876.

26. Astapov, A.N., Kuznetsova, E.L., Rabinskiy, L.N. Operating capacity of anti-oxidizing coating in hypersonic flows of air plasma//Surface Review and Letters, 2019, 26(2), 1850145 p.

27. Rabinskiy, L.N., Tushavina, O.V., Starovoitov, E.I. Study of thermal effects of electromagnetic radiation on the environment from space rocket activity // INCAS Bulletin, 2020, 12(Special Issue), p. 141-148.

28. Babaytsev, A.V., Orekhov, A.A., Rabinskiy, L.N. Properties and microstructure of AlSi10Mg samples obtained by selective laser melting// Nanoscience and Technology: An International Journal, 2020, 11(3), p. 213-222.

29. Anikin V.A., Vyshinsky V.V., Pashkov O.A., et al. Using the maximum pressure principle for verification of calculation of stationary subsonic flow. Herald of the Bauman Moscow State Technical University, Series Mechanical Engineering, 2019, no. 6, pp. 4-16.

30. Antufev, B.A., Egorova, O.V., Rabinskiy, L.N. Quasi-static stability of a ribbed shell interacting with moving load// INCAS Bulletin, 2019, 11, p. 33-39.

31. Egorova, O.V., Kyaw, Y.K. Solution of inverse non-stationary boundary value problems of diffraction of plane pressure wave on convex surfaces based on analytical solution//Journal of Applied Engineering Science, 2020, 18(4), p. 676-680.

32. Formalev, V.F., Kartashov, E.M., Kolesnik, S.A. On the Dynamics of Motion and Reflection of Temperature Solitons in Wave Heat Transfer in Limited Regions // Journal of Engineering Physics and Thermophysics, 2020, 93(1), p. 10-15.

33. Zaripov R.N., Murakaev I.M., Novikov S.V., Ryapukhin A.V. Corporate Structure for Innovative Enterprises, Russian Engineering Research, 2020,Vol. 40, I. 2, pp. 137-139.

34. BurovaA.Yu.,Ryapukhin A.V.,Muntyan A.R. Reduced hardware costs with software and hardware implementation of digital methods multistage discrete Fourier transform on programmable logic devices, Amazonia Investiga, 2020, Vol. 9, I. 27, pp. 227-233.

35. B.A. Garibyan. Modelling of Technical Parameters of Discharge Reactor for Polymer Treatment, International Journal of Pharmaceutical Research, 2020, Vol. 12, Supplementary Issue 2, pp. 1833 1837.

36. Formalev, V.F., Bulychev, N.A., Kuznetsova, E.L., Kolesnik, S.A. The Thermal State of a Packet of Cooled Microrocket Gas-Dynamic Lasers // Technical Physics Letters, 2020, 46(3), p. 245-248.

37. Rabinskiy, L.N., Tushavina, O.V., Formalev, V.F. Mathematical modeling of heat and mass transfer in shock layer on dimmed bodies at aerodynamic heating of aircraft// Asia Life Sciences, 2019, (2), p. 897-911. 